\title{
ASSIGNMENT OF THE MYELOPEROXIDASE GENE $M P O$ TO HUMAN CHROMOSOME 17 USING SOMATIC CELL HYBRIDS AND FLOW-SORTED CHROMOSOMES
}

\author{
Jun Kudoh, ${ }^{1}$ Shinsei Minoshima, ${ }^{1}$ Kazuya HashinaKa, ${ }^{2}$ \\ Chika Nishio, ${ }^{2}$ Michiyuki Yamada, ${ }^{2}$ Yoshiko Shimizu, ${ }^{3}$ \\ and Nobuyoshi SHImizu ${ }^{1,3}$, * \\ ${ }^{1}$ Department of Molecular Biology, Keio University School of Medicine, \\ 35 Shinanomachi, Shinjuku-ku, Tokyo 160, Japan \\ ${ }^{2}$ Institute for Protein Research, Osaka University, \\ 3-2 Yamadaoka, Suita, Osaka 565, Japan \\ ${ }^{3}$ Department of Molecular and Cellular Biology, \\ University of Arizona, Tucson, Arizona \\ 85721, USA
}

\begin{abstract}
Summary A cDNA coding for human myeloperoxidase (MPO) was used as a probe to study MPO gene structure and to determine the chromosomal location of the gene in the human genome. Southern blot hybridization of restriction endonuclease digests of human DNA with the MPO cDNA probe showed that a single gene for human MPO was present in the human genome. Southern blot hybridization experiments with human-mouse cell hybrid DNAs containing various subsets of human chromosomes revealed that the human MPO gene is located on chromosome 17. This conclusion was supported by DNA spot-blot hybridization using flow-sorted human chromosomes.
\end{abstract}

\section{INTRODUCTION}

Myeloperoxidase (MPO) is a main hemoprotein of human polymorphonuclear leukocytes (Schultz and Kaminker, 1962) and is involved in the chloride ion-mediated bactericidal action of these cells (Klebanoff, 1975). Multiple forms of MPO were isolated from human leukocytes and leukemia HL-60 cells (Yamada et al., 1981; Pember et al., 1983; Morita et al., 1986; Miyasaki et al., 1986). The MPO production in HL-60 cells is suppressed when these cells are induced for differentiation by several agents such as a tumor promoter, 12-O-tetradecanoylphorbol-13-acetate

Received March 30, 1988; revised version received May 17, 1988; Accepted May 19, 1988

* To whom correspondence should be addressed. 
TPA, retinoic acid and dimethyl sulfoxide (Yamada et al., 1987; Johnson et al., 1987; Weil et al., 1987) and therefore the presence or absence of MPO is considered as a marker for determining malignancy of leukemic cells. The MPO consists of two large subunits of 59,000 daltons and two small subunits of 15,000 daltons (Yamada et al., 1981; Andrews and Krinsky, 1981). The two large subunits are linked by a disulfide bond (Andrews and Krinsky, 1981; Morita et al., 1986).

We recently isolated cDNA coding for the carboxyl terminal portion of human MPO from a cDNA library of HL-60 cells (Yamada et al., 1987). The other groups have also isolated and characterized cDNAs coding for human MPO (Chang et al., 1986; Johnson et al., 1987; Weil et al., 1987; Morishita et al., 1987). In this communication we have used the cloned human MPO cDNA as a hybridization probe to examine the segregation of the MPO gene in a panel of human-mouse cell hybrids by Southern blot analysis of cell hybrid DNA. The human MPO gene was assigned to chromosome 17. DNA spot-blot analysis of flow-sorted human metaphase chromosomes also supported this conclusion.

\section{MATERIALS AND METHODS}

DNA probes. The cDNA clone, pMP1, encoding carboxy-terminus of human MPO was isolated from a cDNA library constructed from HL-60 cell poly(A) ${ }^{+}$RNA in pBR322 as described previously (Yamada et al., 1987). The cDNA contained 1,278 base pairs (bp) and was composed of three $P_{s t} \mathrm{I}$ fragments of 430,654 and 194 bp (Yamada et al., 1987). The PstI fragment of 654 bp shown in Fig. 1 was isolated from a $P$ st I digest of pMP1 DNA by agarose gel electrophoresis. A 440-bp $K p n \mathrm{I}-X b a \mathrm{I}$ fragment specific for human c-erbB-2 (Semba et al., 1985) was isolated from pKX044 obtained from Japanese Cancer Research Resources Bank (JCRB). DNA probes were labeled with $\left[\alpha^{-32} \mathrm{P}\right] \mathrm{dCTP}$ (Amersham) by random primer extension (Feinberg and Vogelstein, 1983) and used for blot hybridization.

Human-mouse cell hybrid DNAs. A panel of 14 human-mouse cell hybrids containing various subsets of human chromosome was constructed as described previously (Shimizu et al., 1980). High molecular weight DNAs from the cell hybrids, mouse A9 cells and human placenta were isolated as described previously (Hunts et al., 1985).

Southern blot analysis. DNA was completely digested with a restriction endonuclease and fractionated by electrophoresis through a $0.7 \%$ agarose gel. DNA fragments were transferred to nitrocellulose filter (Schleicher \& Schuell, BA85) by the method of Southern (1975). The filters were prehybridized for $6-14 \mathrm{hr}$ at $42^{\circ} \mathrm{C}$ in $50 \%$ formamide, $5 \times \mathrm{SSC}(1 \times \mathrm{SSC}$ consisted of $0.15 \mathrm{M} \mathrm{NaCl}$ and $0.015 \mathrm{M}$ trisodium citrate, $\mathrm{pH} 7.0), 5 \times$ Denhardt's solution, $50 \mathrm{~mm}$ sodium phosphate $(\mathrm{pH} 6.5), 0.1 \%$ sodium dodecyl sulfate (SDS) and $100 \mu \mathrm{g} / \mathrm{ml}$ denatured salmon sperm DNA. The hybridization buffer contains 4 parts of $50 \%$ formamide, $5 \times \mathrm{SSC}, 1 \times$ Denhardt's solution, $50 \mathrm{~mm}$ sodium phosphate (pH 6.5), $0.1 \% \mathrm{SDS}, 100 \mu \mathrm{g} / \mathrm{ml}$ denatured salmon 
sperm DNA and 1 part of $50 \%$ dextran sulfate. The filters were hybridized with ${ }^{32} \mathrm{P}-$ labeled probe for $20-24 \mathrm{hr}$ at $42^{\circ} \mathrm{C}$. After hybridization, the filters were washed twice for $15 \mathrm{~min}$ in $2 \times \mathrm{SSC}-0.1 \% \mathrm{SDS}$ at room temperature, twice for $30 \mathrm{~min}$ in $0.5 \times \mathrm{SSC}-0.1 \% \mathrm{SDS}$ at $50^{\circ} \mathrm{C}$ and twice for $30 \mathrm{~min}$ in $0.1 \times \mathrm{SSC}-0.1 \% \mathrm{SDS}$ at room temperature, and autoradiographed with intensifier screen on Fuji RX X-ray film at $-70^{\circ} \mathrm{C}$.

Spot-blot analysis of flow-sorted chromosomes. Spontaneously transformed human B-lymphoblast line, GM130B, was obtained from the Human Genetic Mutant Cell Repository (Camden, N.J., USA) and used for sorting human chromosomes. The methods for metaphase chromosome preparation, chromosome sorting and spotblot hybridization were carried out according to Lebo et al. (1985) with some modifications. Briefly, metaphase chromosomes were stained with Hoechst 33258 and sorted into 16 fractions by a FACS440 cell sorter (Becton-Dickinson). Fifty thousand chromosomes of each type were sorted directly onto nitrocellulose filter discs (25-mm diameter; Schleicher \& Schuell, BA85) where the chromosomal DNA was denatured and used for hybridization as described above except that washings were twice for $30 \mathrm{~min}$ in $0.1 \times \mathrm{SSC}-0.1 \% \mathrm{SDS}$ at $60^{\circ} \mathrm{C}$ for MPO CDNA probe or twice for $30 \mathrm{~min}$ in $0.5 \times \mathrm{SSC}-0.1 \% \mathrm{SDS}$ at $60^{\circ} \mathrm{C}$ for c-erb $\mathrm{B}-2$ probe. These washing conditions were chosen to assure that the primary gene sequence gives a considerably intenser signal than homologous gene sequences.

\section{RESULTS}

DNAs from human placenta and mouse A9 cells were digested with either restriction endonuclease EcoRI or HindIII. A Southern blot of the digests was hybridized with a pMP1 Pst I fragment of $654 \mathrm{bp}$ encoding carboxy-terminus of human MPO (Fig. 1). As shown in Fig. 2, MPO cDNA strongly hybridized to the 20-kb EcoRI fragment (lane 1) and the 15-kb HindIII fragment (lane 3) in human DNA. These results suggest that a single MPO gene is present in the human genome. Several minor bands were also observed in both the Eco RI and HindIII digests under the hybridization conditions used, suggesting that there may exist several MPOrelated sequences in the human genome. In the digest of the mouse cell line A9 DNA, a single 8-kb EcoRI fragment (lane 2) and a single 8.4-kb HindIII fragment (lane 4) were detected. This represents cross-hybridization of the human MPO probe with a homologous sequence in the mouse genome.

For chromosome assignment of the human MPO gene, a panel of 14 humanmouse cell hybrids were used. DNA from the hybrids was digested with EcoRI and blot hybridized with the human MPO probe. The 20-kb EcoRI fragment (arrows in Fig. 3) specific for human MPO gene was detected in 10 hybrids (TA4, TA5, B4A1-17a, C3B4, D5B1, B5B2, B4A4, B2B4, B4B4 and B2B1) out of 14. Four hybrids (TA1, TA2, TA3 and C2B5) were negative. The chromosomal profile of the hybrid cells was compared to the results of the Southern blot analysis, as shown 


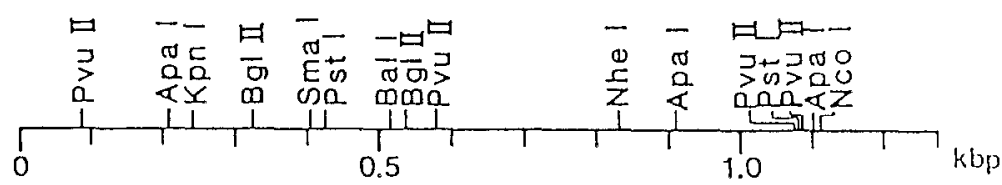

\section{Probe}

Fig. 1. Restriction enzyme map of MPO cDNA. The cDNA clone, pMP1, encoding the carboxy-terminus of human myeloperoxidase (MPO) was isolated from a cDNA library constructed from HL-60 cell poly(A)+ RNA in pBR322 as described previously (Yamada et al., 1987). The upper line indicates a detailed restriction map of the cDNA. The cDNA consists of $1,278 \mathrm{bp}$ containing an open reading frame of $474 \mathrm{bp}$ and a noncoding region of $804 \mathrm{bp}$. The middle line indicates the position of the open reading frame (the boxed area). The Pst I fragment of $654 \mathrm{bp}$, shown in the lower line, was labeled with ${ }^{32} \mathrm{P}$ by random primer extension and used as a probe for blot hybridization.

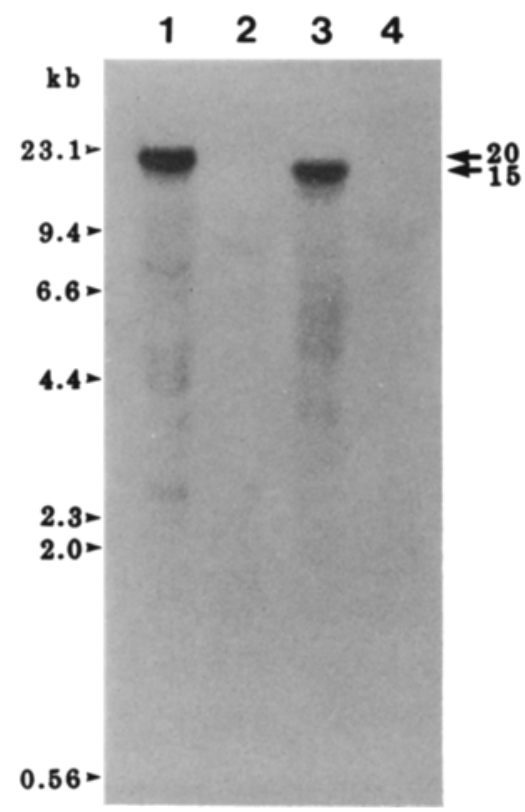

Fig. 2. Southern blot analysis of the myeloperoxidase (MPO) gene. DNAs ( $5 \mu$ g each) from human placenta (lanes 2 and 3) and mouse A9 cells (lanes 2 and 4) were digested with either EcoRI (lanes 1 and 2) or HindIII (lanes 3 and 4) and analyzed by Southern hybridization using MPO cDNA as a probe (see Fig. 1). HindIIIdigested lambda phage DNA was used as a size marker and the sizes are shown in kilobases $(\mathrm{kb})$. 


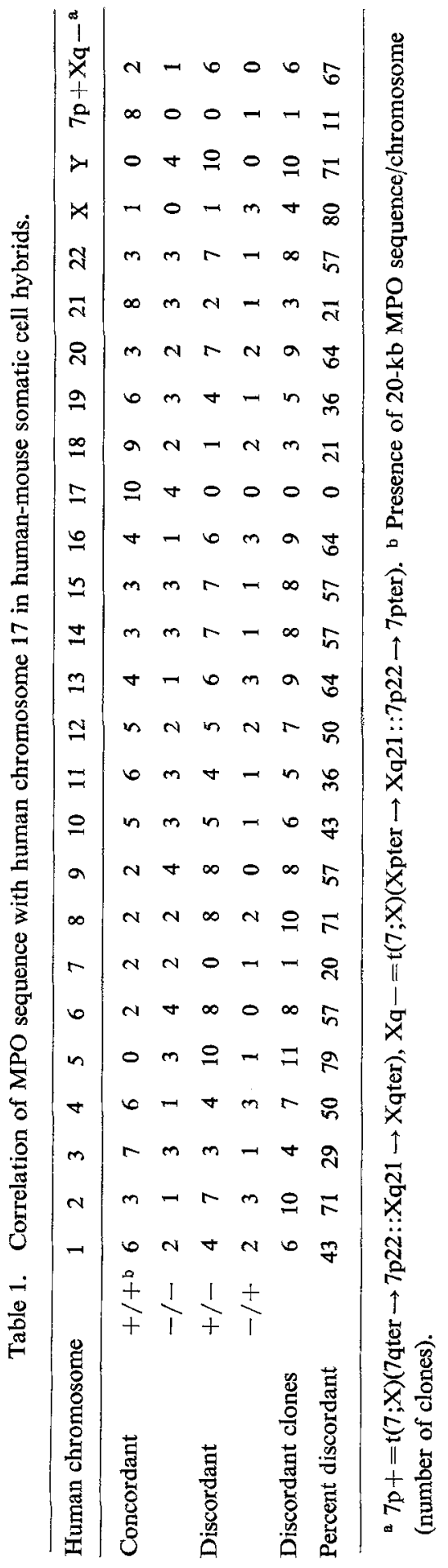

Vol. 33, No. 3, 1988 

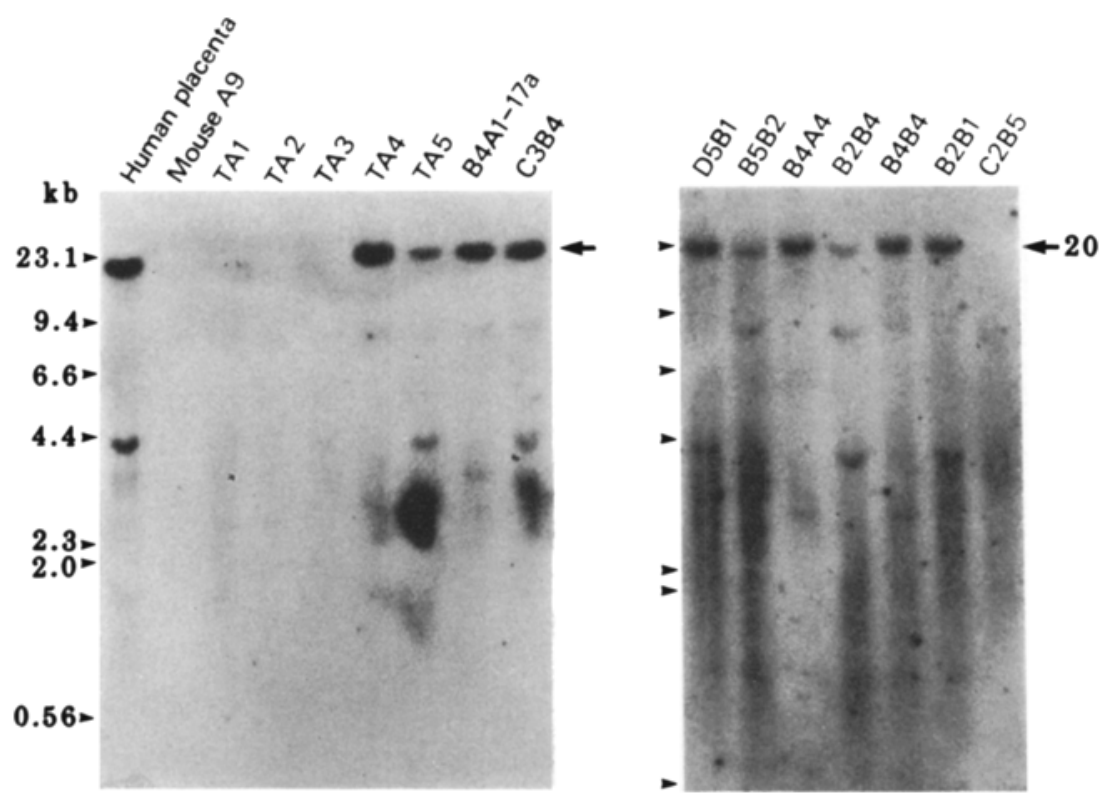

Fig. 3. Southern blot analysis of EcoRI-digested DNAs from human-mouse cell hybrids using the human MPO cDNA probe. DNAs ( $5 \mu \mathrm{g}$ each) from human placenta, the mouse cell line A9 and 14 clones of human-mouse cell hybrids were digested with EcoRI and analyzed by Southern hybridization using ${ }^{32} \mathrm{P}$-labeled human MPO cDNA probe (see Fig. 1).

in Table 1. We found that the presence of human chromosome 17 corresponds to the presence of the 20-kb MPO sequence. The absence of human chromosome 17 correlated with the absence of the $20-\mathrm{kb}$ MPO sequence. The other chromosomes could be eliminated with discordances of greater than $11 \%$. These results indicate that the MPO gene is located on human chromosome 17.

To confirm the localization of the MPO gene on chromosome 17, we carried out DNA spot-blot analysis of flow-sorted human metaphase chromosomes. Metaphase chromosomes were prepared from human B-lymphoblast line GM130B, stained with Hoechst 33258, then analyzed and sorted by a FACS440 cell sorter. As shown in Fig. 4(A), these chromosomes were fractionated into 16 groups, A through O, containing one to four types of chromosomes. Fifty thousand chromosomes of each type in each group were sorted directly onto nitrocellulose filter discs. Chromosomal DNA immobilized on filter discs were hybridized with the human MPO probe. As shown in Fig. 4(B), the most intense signal was obtained with DNA from the group $\mathrm{L}$ containing chromosome 17 and $\mathrm{Y}$. The hybridization experiment using a 440-bp KpnI-XbaI fragment of human c-erbB-2 gene (Semba et al., 1985) assigned to chromosome 17 (Schechter et al., 1985; Coussens et al., 1985; Fukushige et al., 1986) as a probe confirmed the presence of chromosome 17 in the group $\mathrm{L}$ as shown in 


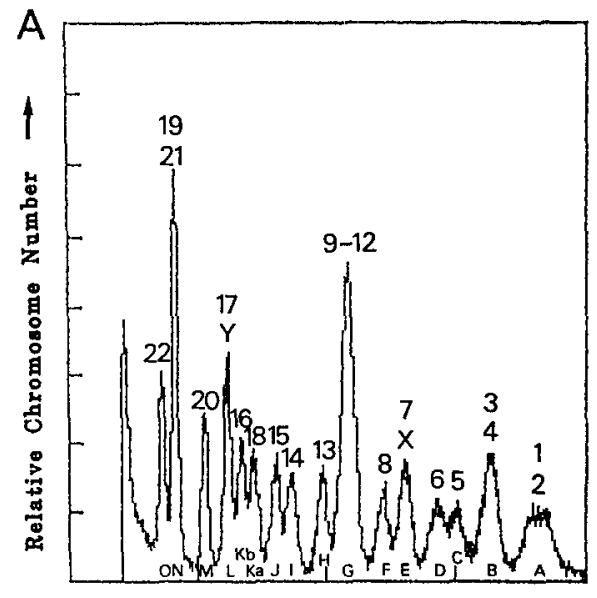

Relative Fluoregcence of Hoechat $33258 \rightarrow$

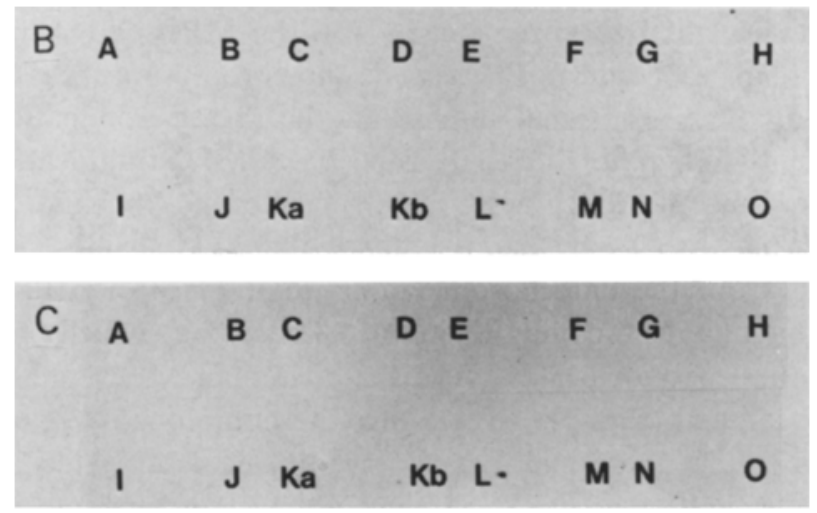

Fig. 4. Spot-blot analysis of flow-sorted human chromosomes. (A) Flow karyotype of human B-lymphoblast line GM130B. Numbers in the figure represent the positions of human chromosomes. (B, C) Fifty thousand chromosomes of each type in each group shown in (A) were directly sorted onto nitrocellulose filter discs. Hybridization was carried out with either the MPO cDNA probe (B) or the c-erbB2 probe $(C)$.

Fig. 4(C). Weak signals in the group $\mathrm{Kb}$, detected by the MPO and c-erbB-2 probes, may represent contamination from the neighboring group $\mathrm{L}$. These results together with cell hybrid analysis indicate that the MPO gene is located on human chromosome 17.

\section{DISCUSSION}

MPO consists of two large subunits and two small subunits (Yamada et al., 1981; Andrews and Krinsky, 1981). Studies on the biosynthesis of MPO have shown 
that these large and small subunits are generated from a single polypeptide chain precursor (Yamada, 1982; Olsson et al., 1984; Koeffler et al., 1985; Akin and Kinkade, 1986). Our present study provided evidence that MPO is synthesized from a gene located on chromosome 17. The chromosome assignment based on the segregation of the MPO gene in a panel of human-mouse cell hybrids was confirmed because the same segregation pattern was obtained when a marker for chromosome 17 (Schechter et al., 1985; Coussens et al., 1985; Fukushige et al., 1986), a 440-bp KpnI-XbaI fragment of human c-erbB-2 gene (Semba et al., 1985), was used as a probe (data not shown). Also, spot-blot hybridization using flow-sorted human chromosomes provided a definitive evidence for the assignment.

Southern blot analysis of human leukemia HL-60 cell DNA with the MPO CDNA probe indicated that the fragments detected in the Eco RI digests are identical in number, size and signal intensities to those in the placenta DNA (data not shown). Thus, the MPO gene was not rearranged and not amplified in leukemia HL-60 cells as reported by others (Chang et al., 1986; Morishita et al., 1987).

Several minor bands hybridized weakly with an MPO cDNA probe as shown in Fig. 3. Although we could not determine the chromosome localization of these bands because of their low signal intensities, the segregation pattern of some of these was apparently different from that of the $20-\mathrm{kb}$ MPO fragment. For example, a hybrid cell TA4 had the $20-\mathrm{kb}$ MPO band, but not $4.4-\mathrm{kb}$ band. In contrast, a hybrid cell TA3 had the $4.4-\mathrm{kb}$ band, but not the $20-\mathrm{kb}$ band. Thus the $4.4-\mathrm{kb}$ must be derived from the chromosome other than 17. An MPO cDNA probe used in this study contains a coding region of 48 base pairs which corresponds to 16 amino acid residues of the carboxyl terminal of human MPO and a $3^{\prime}$ noncoding region of 610 base pairs (Fig. 1). Therefore, the homologous regions between the MPO cDNA probe and these minor bands are not necessarily localized within the coding region of MPO. Molecular cloning and further characterization of these bands are needed to reveal the significance of these sequence homology.

Acknowledgments The authors wish to thank Ms. H. Harigai for her assistance in manuscript preparation. This work was supported in part by a Grant-in-Aid from the Ministry of Education, Science and Culture of Japan and by a grant from National Institute of Health.

\section{REFERENCES}

Akin, D.T. and Kinkade, J.M., Jr. 1986. Processing of a newly identified intermediate of human myeloperoxidase in isolated granules occurs at neutral pH. J. Biol. Chem. 261: 8370-8375.

Andrews, P.C. and Krinsky, N.I. 1981. The reductive cleavage of myeloperoxidase in half, producing enzymically active hemi-myeloperoxidase. J. Biol. Chem. 256: 4211-4218.

Chang, K.S., Trujillo, J.M., Cook, R.G., and Stass, S.A. 1986. Human myeloperoxidase gene: Molecular cloning and expression in leukemic cells. Blood 68: 1411-1414.

Coussens, L., Yang-Feng, T.L., Liao, Y.-C., Chen, E., Gray, A., McGrath, J., Seeburg, P.H., Libermann, T.A., Schlessinger, J., Francke, U., Levinson, A., and Ullrich, A. 1985. Tyrosine kinase receptor with extensive homology to EGF receptor shares chromosomal location with neu oncogene. Science 230: 1132-1139. 
Feinberg, A.P. and Vogelstein, B. 1983. A technique for radiolabeling DNA restriction endonuclease fragments to high specific activity. Anal. Biochem. 132: 6-13.

Fukushige, S., Matsubara, K., Yoshida, M., Sasaki, M., Suzuki, T., Semba, K., Toyoshima, K., and Yamamoto, T. 1986. Localization of a novel v-erbB-related gene, c-erbB-2, on human chromosome 17 and its amplification in a gastric cancer cell line. Mol. Cell. Biol. 6: 955-958.

Hunts, J.H., Shimizu, N., Yamamoto, T., Toyoshima, K., Merlino, G.T., Xu, Y.-H., and Pastan, I. 1985. Translocation chromosome 7 of A431 cells contains amplification and rearrangement of EGF receptor gene responsible for production of variant mRNA. Somat. Cell Mol. Genet. 11: $477-484$.

Johnson, K.R., Nauseef, W.M., Care, A., Wheelock, M.J., Shane, S., Hudson, S., Koeffler, H.P., Selsted, M., Miller, C., and Rovera, G. 1987. Characterization of cDNA clones for human myeloperoxidase: Predicted amino acid sequence and evidence for multiple mRNA species. Nucleic Acids Res. 15: 2013-2028.

Klebanoff, S.J. 1975. Antimicrobial mechanisms in neutrophilic polymorphonuclear leukocytes. Semin. Hematol. 12: 117-142.

Koeffler, H.P., Ranyard, J., and Pertcheck, M. 1985. Myeloperoxidase: Its structure and expression during myeloid differentiation. Blood 65: 484-491.

Lebo, R.V., Tolan, D.R., Bruce, B.D., Cheung, M.-C., and Kan, Y.W. 1985. Spot-blot analysis of sorted chromosomes assigns a fructose intolerance disease locus to chromosome 9. Cytometry 6: 478-483.

Miyasaki, K.T., Wilson, M.E., Cohen, E., Jones, P.C., and Genco, R.J. 1986. Evidence for and partial characterization of three major and three minor chromatographic forms of human neutrophil myeloperoxidase. Arch. Biochem. Biophys. 246: 751-764.

Morishita, K., Kubota, N., Asano, S., Kajiro, Y., and Nagata, S. 1987. Molecular cloning and characterization of cDNA for human myeloperoxidase. J. Biol. Chem. 262: 3844-3851.

Morita, Y., Iwamoto, H., Aibara, S., Kobayashi, T., and Hasegawa, E. 1986. Crystallization and properties of myeloperoxidase from normal human leukocytes. J. Biochem. 99: 761-770.

Olsson, I., Persson, A.M., and Strömberg, K. 1984. Biosynthesis, transport and processing of myeloperoxidase in the human leukaemic promyelocytic cell line HL-60 and normal marrow cells. Biochem. J. 223: 911-920,

Pember, S.O., Shapira, R., and Kinkade, J.M., Jr. 1983. Multiple forms of myeloperoxidase from human neutrophilic granulocytes: Evidence of differences in compartmentalization, enzymatic activity, and subunit structure. Arch. Biochem. Biophys. 221: 391-403.

Schechter, A.J., Hung, M.-C., Vaidyanathan, L., Weinberg, R.A., Yang-Feng, T.L., Franke, U., Ullrich, A., and Coussens, L. 1985. The neu gene: An erbB-homologous gene distinct from and unlinked to the gene encoding the EGF receptor. Science 229: 976-978.

Schultz, J. and Kaminker, K. 1962. Myeloperoxidase of the leucocyte of normal human blood. I. Content and localization. Arch. Biochem. Biophys. 96: 465-467.

Semba, K., Kamata, N., Toyoshima, K., and Yamamoto, T. 1985. A v-erbB-related protooncogene, $\mathrm{c}-\mathrm{er} b \mathrm{~B}-2$, is distinct from the c-erbB-1/epidermal growth factor-receptor gene and is amplified in a human salivary gland adenocarcinoma. Proc. Natl. Acad. Sci. USA 82: 6497-6501.

Shimizu, N., Behzadian, M.A., and Shimizu, Y. 1980. Genetics of cell surface receptor for bioactive polypeptides: Binding of epidermal growth factor is associated with the presence of human chromosome 7 in human-mouse cell hybrids. Proc. Natl. Acad. Sci. USA 77: 3600-3604.

Southern, E.M. 1975. Detection of specific sequences among DNA fragments separated by gel electrophoresis. J. Mol. Biol. 98: 503-517.

Weil, S.C., Rosner, G.L., Reid, M.S., Chisholm, R.L., Farber, N.M., Spitznagel, J.K., and Swanson, M.S. 1987. cDNA cloning of human myeloperoxidase: Decrease in myeloperoxidase mRNA upon induction of HL-60 cells. Proc. Natl. Acad. Sci. USA 84: 2057-2061. 
Yamada, M., Mori, M., and Sugimura, T. 1981. Purification and characterization of small molecular weight myeloperoxidase from human promyelocytic leukemia HL-60 cells. Biochemistry 20: $766-771$.

Yamada, M. 1982. Myeloperoxidase precursors in human myeloid leukemia HL-60 cells. J. Biol. Chem. 257: 5980-5982.

Yamada, M., Hur, S.-J., Hashinaka, K., Tsuneoka, K., Saeki, T., Nishio, C., Sakiyama, F., and Tsunasawa, S. 1987. Isolation and characterization of a cDNA coding for human myeloperoxidase. Arch. Biochem. Biophys. 255: 147-155. 